OPEN

SUBJECT AREAS:

GLASSES

SOLAR CELLS

WETTING

METALS AND ALLOYS

Received

18 March 2013

Accepted

18 June 2013

Published

15 July 2013

Correspondence and requests for materials should be addressed to E.S.L. (e.lee@samsung. com) or D.H.K. (dohkim@yonsei.ac.kr)

* These authors contributed equally to this work.

$\uparrow$ Current address: Light Metal Division,

Korea Institute of

Materials Science,

797 Changwondaero,

Seongsan-gu,

Changwon,

Gyeongnam 642-831,

Republic of Korea

\section{Capillary flow of amorphous metal for high performance electrode}

\author{
Se Yun Kim ${ }^{1 *}$, Suk Jun Kim ${ }^{*}$, Sang Soo Jee', Jin Man Park', Keum Hwan Park', Sung Chan Park², \\ Eun $\mathrm{Ae} \mathrm{Cho}^{3}$, Jun Ho Lee ${ }^{3}$, In Yong Song ${ }^{3}$, Sang Mock Lee', In Taek Han' ${ }^{1}$ Ka Ram Lim ${ }^{4} \uparrow$, Won Tae Kim", \\ Ju Cheol Park' ${ }^{6}$, Jürgen Eckert ${ }^{7}$, Do Hyang Kim ${ }^{4}$ \& Eun-Sung Lee ${ }^{1}$
}

\begin{abstract}
'Materials R\&D Center, Samsung Advanced Institute of Technology (SAIT), San \# 14-1, Nongseo-dong, Giheung-gu, Yongin-si, Gyeonggi-do 446-71 2, Republic of Korea, ${ }^{2}$ Samsung SDI CO. LTD, San \#24, Nongseo-dong, Giheung-gu, Yongin-si, Gyeonggi-do 446-71 1, Republic of Korea, ${ }^{3}$ Computational \& Analytical Science Center, Samsung Advanced Institute of Technology, San \# 14-1, Nongseo-dong, Giheung-gu, Yongin-si, Gyeonggi-do 446-712, Republic of Korea, ${ }^{4}$ Department of Materials Science and Engineering, Yonsei University, 134 Shinchon-dong, Seodaemun-ku, Seoul, 120-749, Republic of Korea, ${ }^{5}$ Department of Optical Engineering, Cheongju University, 36 Naedock-dong, Cheongiu, Chungbuk, 360-764, Republic of Korea, ${ }^{6}$ Research Institute for Advanced Materials, Seoul National University, Kwanak-ro 599, Kwanak-gu, Seoul, 151-742, Republic of Korea, ${ }^{7}$ Institute for Complex Materials, IFW Dresden, P.O. Box 2701 16, D-0 1171 Dresden, Germany and Institute of Materials Science, TU Dresden, D-01062 Dresden, Germany.
\end{abstract}

Metallic glass (MG) assists electrical contact of screen-printed silver electrodes and leads to comparable electrode performance to that of electroplated electrodes. For high electrode performance, MG needs to be infiltrated into nanometer-scale cavities between $\mathrm{Ag}$ particles and reacts with them. Here, we show that the MG in the supercooled state can fill the gap between Ag particles within a remarkably short time due to capillary effect. The flow behavior of the MG is revealed by computational fluid dynamics and density funtional theory simulation. Also, we suggest the formation mechanism of the Ag electrodes, and demonstrate the criteria of $M G$ for higher electrode performance. Consequently, when $\mathrm{Al}_{85} \mathrm{Ni}_{5} \mathrm{Y}_{8} \mathrm{Co}_{2} \mathrm{MG}$ is added in the Ag electrodes, cell efficiency is enhanced up to $20.30 \%$ which is the highest efficiency reported so far for screen-printed interdigitated back contact solar cells. These results show the possibility for the replacement of electroplating process to screen-printing process.

(1) ue to the strong demands for high performance electrodes in modern electronic devices, there have been many efforts to form electrodes using various methods such as screen printing, electroplating and deposition processes ${ }^{1-4}$. Among these processes, screen printing process has the great advantage in commercializing the products due to its much higher cost-effectiveness 5 . However, the electrodes formed by the printing process exhibit lower electrical conductance than those by electroplating and deposition processes. To enhance the electrode performance of the printed electrodes, a special glass frit is to be included in the Ag paste, and should satisfy the following conditions for highly conductive contact formation: 1) the glass frit should be able to be fill the cavity between the Ag particles at the temperature as low as possible; 2) it should react with $\mathrm{Ag}$ particles and $\mathrm{Si}$ substrate as fast as possible; and 3) it should have electrical resistance as low as possible. So far, oxide glass (OG) frit has been used to assist the Ag sintering and the contact formation between the electrode and the Si substrate ${ }^{6}$. Nevertheless, there is a critical limitation for the OG frit to form a high performance electrode, since the OG has a very poor electrical conductance. To overcome the limitation of the electrodes formed by the printing process, we have replaced the OG with metallic glass $(\mathrm{MG})^{7-9}$. Since MGs consist of mostly metallic elements, their conductance is approximately $10^{14}$ times higher than that of the OGs $s^{10,11}$. Moreover, MGs have some desirable characteristics such as the presence of a wide super-cooled liquid (SCL) region ${ }^{12}$ and the outstanding thermoplastic formability which can satisfy the above-mentioned conditions critically required for enhanced solar cell efficiency ${ }^{13-16}$. In particular, it has been shown that even nanometer-sized channels can be filled with SCL in a controllable way when the viscosity is low enough and the capillary effect is present ${ }^{16}$. Here, we show that the application of Al-based MG instead of the OG in forming the printed electrodes can significantly enhance the solar cell efficiency comparable to that obtained by electroplating or deposition process. Since the details of the flow behaviour of the MG in the Ag printing electrodes have not been disclosed yet, we performed CFD (Computational Fluid Dynamics) and DFT (Density Funtional Theory) simulation. Furthermore, we have 
proposed the electrode contact formation mechanism, and demonstrated the criteria of the MG to enhance the performance of the silver printed electrodes.

\section{Results}

Flow behavior of metallic glass. Generally, the electrode paste consists of conductive metal particle, glass frit, additives and organic vehicles ${ }^{17}$. We selected Ag as an element for the conductive particle and Al-based MG particle as an alternative to the OG frit particle due to its superior electrical conductance. Among the glass forming Al-based alloys, the $\mathrm{Al}_{85} \mathrm{Ni}_{5} \mathrm{Y}_{8} \mathrm{Co}_{2}$ alloy was selected since the SCL region $\left(\Delta \mathrm{T}_{\mathrm{x}}\right)$ during heating is relatively large $\left(\Delta \mathrm{T}_{\mathrm{x}}=\mathrm{T}_{\mathrm{x}}-\right.$ $\mathrm{T}_{\mathrm{g}}: 24 \mathrm{~K}$, glass transition temperature $\mathrm{T}_{\mathrm{g}}: 535 \mathrm{~K}$, crystallization onset temperature $\mathrm{T}_{\mathrm{x}}: 559 \mathrm{~K}$ at a heating rate of $40 \mathrm{~K} / \mathrm{min}$, Fig. $\left.1 \mathrm{a}\right)^{8}$. The electrode paste was prepared by mixing $\mathrm{Ag}$ particles, $\mathrm{Al}_{85} \mathrm{Ni}_{5} \mathrm{Y}_{8} \mathrm{Co}_{2}$ MG particles and organic vehicles. The electrode pattern was prepared by screen printing the paste on single crystalline Si wafers and then fired by rapid heating from room temperature up to $873 \mathrm{~K}$ with a heating rate of $75 \mathrm{~K} / \mathrm{s}$.

Our approach for achieving high cell efficiency is based on the unique characteristics of the metallic glass: the metallic glass in the SCL state can infiltrate into a nanometer-scale cavity when a proper wetting condition is provided, i.e. wetting angle $(\theta)$ is $<90^{\circ}$, and viscosity of the SCL is low, i.e. the SCL region is wide ${ }^{16}$. Kumar et al. reported a modified Hagen-Poiseuille's equation to determine the pressure required for MG to flow into nanometer-scale mould ${ }^{16}$. A prerequisite to obtain a high cell efficiency is that the MG should spontaneously fill the cavity between the Ag particles during the early stage of the firing process. Since there is no external pressure during the firing process, the condition for the SCL to fill the channel between the Ag particles can be derived by modifying the equation suggested by Kumar et al.(Supplementary Information I):

$$
t_{\text {fill }}=\frac{3 \eta d}{\gamma \cos \theta} \leq \frac{\Delta T_{x}}{R_{\text {heat }}}=t_{S C L}
$$

Here, $t_{\text {fill }}$ is the time required for the SCL to infiltrate into the channel between the Ag particles, $\eta$ is the viscosity of the SCL, $d$ is the diameter of the Ag particle, $\gamma$ is the surface tension of the MG, $\theta$ is the contact angle between the SCL and the Ag particle, $\Delta \mathrm{T}_{\mathrm{x}}$ is the SCL region of the $M G, R_{\text {heat }}$ is the heating rate during the firing process, and $t_{S C L}$ is the time available for the MG to stay in the SCL region during the firing process. $t_{\text {fill }}$ should be smaller than $t_{\mathrm{SCL}}$ for the SCL to completely flow into the channel between the particles.

The flow behavior of the $\mathrm{Al}_{85} \mathrm{Ni}_{5} \mathrm{Y}_{8} \mathrm{Co}_{2} \mathrm{MG}$ in the Ag electrode paste was simulated using a Computational Fluid Dynamics (CFD) program of Fluent 13.0 (ANSYS Inc.). First, the heating rate dependence of the viscosity was evaluated by Thermo Mechanical Analysis (TMA) (Supplementary Information II). The viscosity data measured at a heating rate of $40 \mathrm{~K} / \mathrm{min}$ (Fig. 1b) shows that the viscosity of the MG is $\sim 2 \times 10^{10} \mathrm{~Pa} \cdot \mathrm{s}$ below the $\mathrm{T}_{\mathrm{g}}$, while it is reduced down to $\sim 2 \times 10^{8} \mathrm{~Pa} \cdot \mathrm{s}$ in the SCL region. Comparison of the viscosity data measured at heating rates of $5,10,20$, and $40 \mathrm{~K} / \mathrm{min}$ (Fig. 1c) indicates that the lowest viscosity in the SCL region decreases as the heating rate becomes higher. The lowest viscosity in the SCL region with a heating rate of $75 \mathrm{~K} / \mathrm{s}$ (same as that used for the firing process) is evaluated to be $1.7 \times 10^{5} \mathrm{~Pa} \cdot \mathrm{s}$ by extrapolation of the measured data in a logarithmic scale (Fig. 1c), which is slightly higher than the previously reported viscosity of $3 \times 10^{4} \mathrm{~Pa} \cdot \mathrm{s}$ obtained at a heating rate of $75 \mathrm{~K} / \mathrm{s}$ for La-based $\mathrm{MG}^{18}$. Differential scanning calorimetry (DSC) measurements were also performed at various ramping speed of $5,10,20$, and $40 \mathrm{~K} / \mathrm{min}$ to investigate the heating rate dependence of the SCL region. Since the ramping speed during the firing process is $75 \mathrm{~K} / \mathrm{s}$, the data were extrapolated using Kissinger's equation ${ }^{19}$, and it is derived that $\mathrm{T}_{\mathrm{g}}$ and $\mathrm{T}_{\mathrm{x}}$ are 564 and $604 \mathrm{~K}$, respectively, at the heating rate of $75 \mathrm{~K} / \mathrm{s}$ (Supplementary Information III).

The calculation system for the flow behavior consists of 4 layers of close packed MG and Ag particles. Each of the three layers from the bottom contains one MG particle and $32 \mathrm{Ag}$ particles, while the fourth layer consisted of only Ag particles. (Fig. 2a, Supplementary Information IV for the details on the simulation method). The surface tension of the $\mathrm{Al}_{85} \mathrm{Ni}_{5} \mathrm{Y}_{8} \mathrm{Co}_{2} \mathrm{MG}$ is calculated to be $1045.7 \mathrm{mN}$ / $\mathrm{m}$ using first-principles molecular dynamics (MD) calculation based on the density functional theroy (DFT) (Supplementary Information $\mathrm{V}$ for the details on the simulation method). Figures $2 \mathrm{~b}-2 \mathrm{~d}$ show $\mathrm{a}$ collection of a series of snap-shots with time at three different cross sections of the simulation model. Here, the viscosity of the MG is assumed to be $10^{5} \mathrm{~Pa} \cdot \mathrm{s}$ and the average MG/Ag and MG/Si interfacial energies are calculated to be $181.8 \mathrm{mN} / \mathrm{m}$, and $961.6 \mathrm{mN} / \mathrm{m}$, respectively using ab initio MD method (Supplementary Information $\mathrm{V}$ ). The contact angles of the MG on the Ag particle and the Si substrate are $20.1^{\circ}$ and $76.6^{\circ}$, when the surface tensions of $\mathrm{Ag}$ and $\mathrm{Si}$ are $1164.1 \mathrm{mN} / \mathrm{m}$ and $1204.1 \mathrm{mN} / \mathrm{m}$ at $573 \mathrm{~K}$, respectively ${ }^{20,21}$. Since the contact angles are below $90^{\circ}$, the MG in the SCL state has a reasonably high driving force to spread on the surface of the Ag particles and the Si substrate by the capillary effect. The time availabe for the MG to stay in the SCL state is approximately $0.5 \mathrm{sec}$ when the SCL region of the $M G$ is $40 \mathrm{~K}$ and the heating rate for the firing process is $75 \mathrm{~K} / \mathrm{s}$. It can be seen from Fig. $2 \mathrm{c}$ and $2 \mathrm{~d}$ that the MG in the SCL state begins to flow after $0.1 \mathrm{sec}$, and almost fill the channel between Ag particles after $0.5 \mathrm{sec}$, indicating that the SCL fills the channel between the particles within a remarkably short time. Thus, the MG particle in the electrode paste can fill the channel between the Ag particles when it is in the SCL state during the firing process. Figure $2 \mathrm{~b}$ indicates that the MG particle in the first layer which is in contact with the Si substrate retains the almost spherical shape since the contact angle of the MG on the Si surface is higher than that of the MG on the Ag surface. However, the MG particles in the second and third layer flow into the channel due to the lower contact angle of the MG on the Ag surface.
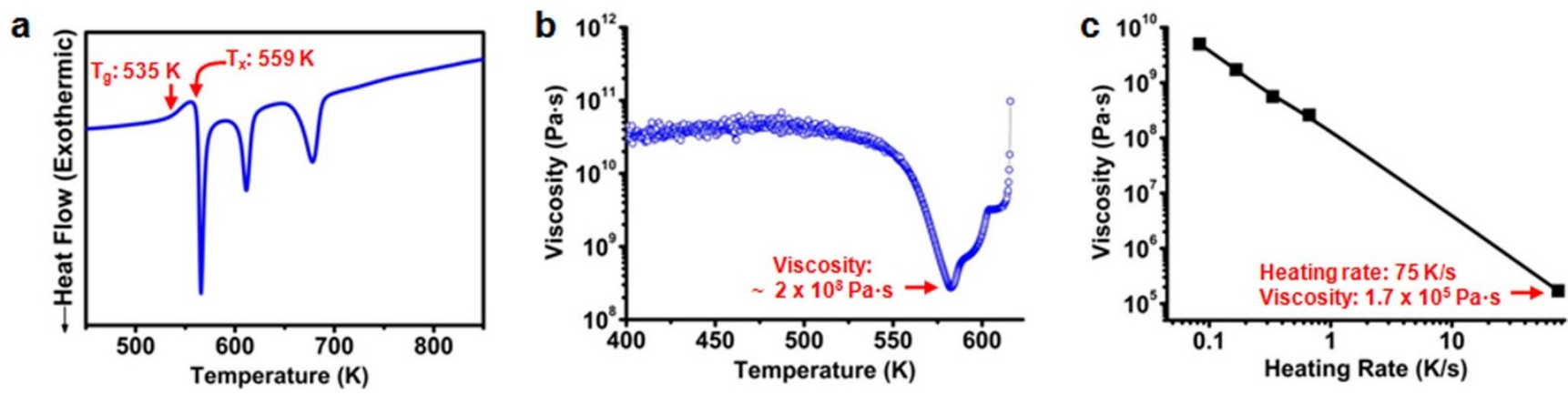

Figure $1 \mid$ Viscosity of $\mathrm{Al}_{85} \mathrm{Ni}_{5} \mathrm{Y}_{8} \mathrm{Co}_{2} \mathrm{MG}$ (Metallic Glass). (a) Differential Scanning Calorimetry (DSC) curve and (b) temperature dependence of the

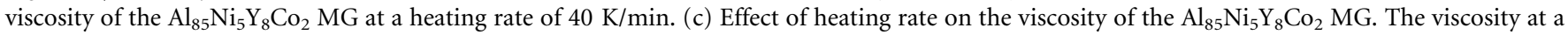
heating rate of $75 \mathrm{~K} / \mathrm{s}$ is evaluated to be $1.7 \times 10^{5} \mathrm{~Pa} \cdot \mathrm{s}$ by extrapolation of the measured data in a logarithmic scale. 

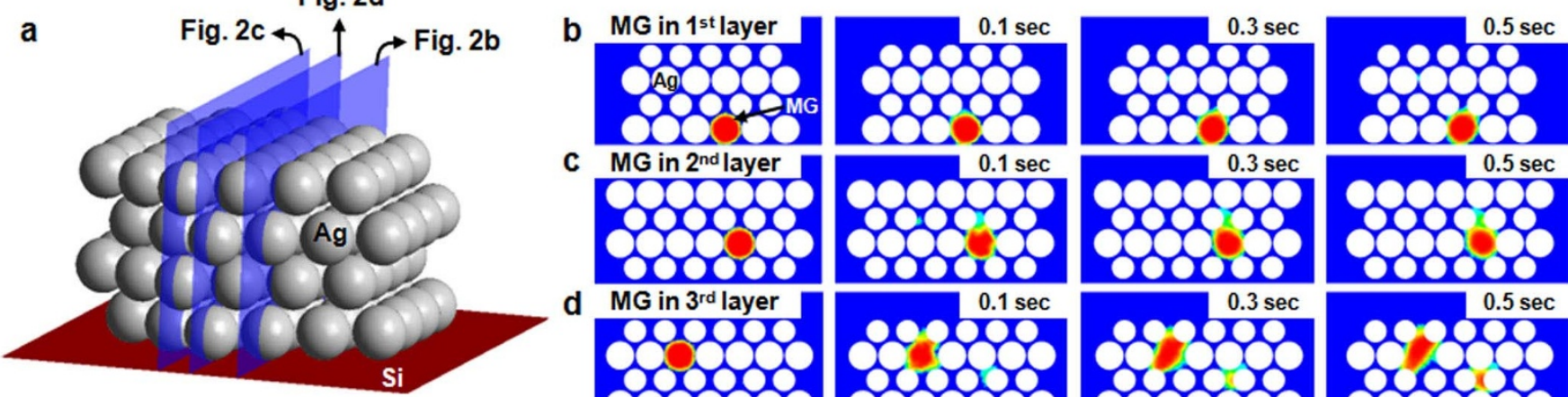

d
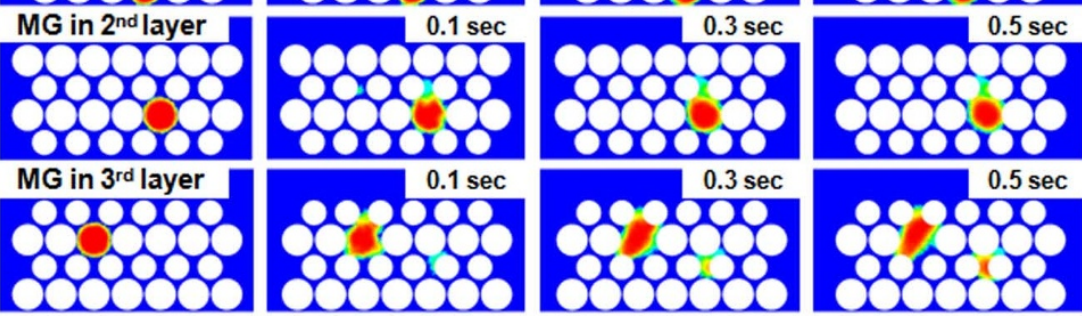

Figure 2 Simulation of MG (Metallic Glass) flow behavior using CFD (Computational Fluid Dynamics) method. (a) Ag electrode model consists of MG and Ag particles on the Si substrate. Each of the three layers from the bottom contains one MG particle and 32 Ag particles, while the fourth layer has only Ag particles. Grey balls, dark red plate, and blue plates represent Ag particles, Si substrate, and cross section planes, respectively. MG volume fraction contour plots are shown at cross sections of the Ag electrode model where the MG particles are located in the (b) first, (c) second, and (d) third layer from the bottom. White balls represent Ag particles. MG volume fraction is displayed with the color ranging from blue (minimum value) to red (maximum value) on the contour plots. The MG particles begin to flow after $0.1 \mathrm{sec}$, and almost fill the gap between the Ag particles after $0.5 \mathrm{sec}$. Spontaneous flow of the MG occurs by the capillary effect due to the low contact angle $\left(\sim 20^{\circ}\right)$ between MG-Ag and the low viscosity $\left(\sim 10^{5} \mathrm{~Pa} \cdot \mathrm{s}\right)$ of the $\mathrm{MG}$ in its supercooled liquid region.

From the DFT simulation and the experimental results mentioned above, the parameters required for equation (1) can be obtained: viscosity of the SCL: $1.7 \times 10^{5} \mathrm{~Pa} \cdot \mathrm{s}$, surface tension of the MG: $1045.7 \mathrm{mN} / \mathrm{m}$, contact angle of the MG on the Ag surface: $20.1^{\circ}$, diameter of $\mathrm{Ag}$ particle: $1 \mu \mathrm{m}$, SCL region: $40 \mathrm{~K}$ and heating rate: $75 \mathrm{~K} / \mathrm{s}$. Equation (1) indicates that the time required for the SCL flow into the channel between the particles, $\mathrm{t}_{\mathrm{fill}}$, is $0.52 \mathrm{sec}$, while the time available for the MG to stay in the SCL state, $t_{\mathrm{SCL}}$, is $0.53 \mathrm{sec}$. Therefore, it is concluded that the MG in the SCL state can fill the channel between the particles by the capillary effect during the firing process. Equation (1) further indicates that lower viscosity of the SCL, larger $\Delta \mathrm{T}_{\mathrm{x}}$ of the MG, and smaller size of the Ag particle is preferred for more efficient filling of the cavity by the capillary effect. Higher heating rate can lower the viscosity, but the time available for the MG to remain in the SCL state becomes shorter, suggesting the presence of optimum heating rate to maximize the infiltration of the SCL.

Electrode formation and contact morphology. Due to the lower $\mathrm{T}_{\mathrm{g}}$ and $\mathrm{T}_{\mathrm{x}}$ of the $\mathrm{Al}_{85} \mathrm{Ni}_{5} \mathrm{Y}_{8} \mathrm{Co}_{2} \mathrm{MG}^{8}$ than for other glass forming systems such as $\mathrm{Cu}$ - and $\mathrm{Zr}$-based $\mathrm{MGs}^{22,23}$, the Al-MG is suitable for low firing-temperature process. Lower firing temperature is particularly important for the back contact solar cell fabrication in minimizing the thermal degradation of the carrier lifetime in the cell ${ }^{24}$. The firing peak temperature attempted in the present study $(873 \mathrm{~K})$ is about $200 \mathrm{~K}$ lower than the typical peak temperature for forming conventional solar cell electrodes using the OG frit.

The electrode formed by the firing process exhibited a continuous network structure implying that the MG frit plays an effective role in sintering of Ag particles (Fig. 3a). Several unique microstructural features can be noticed from the contact achieved with the MG electrode paste. First, the original spherical surface of Ag particles changed into a flat surface, especially at the contact region with the $\mathrm{Si}$ emitter in spite of the lower firing peak temperature (Fig. 3b). Second, an ultra-thin layer with a thickness of $\sim 5 \mathrm{~nm}$ is present between the Ag electrode and the Si emitter (Fig. 3c). The layer is enriched in $\mathrm{Al}$ and $\mathrm{O}$ as shown in the EDS line profile (Fig. 3d). Such contact morphology is strikingly different from that formed using the OG frit in conventional Si solar cells. When the conventional OG frit is used, most of the Ag electrode and the Si emitter are separated by a much thicker highly resistive glass layer with varying thickness, which is responsible for the high contact resistance and therefore the low cell efficiency ${ }^{25}$. Third, no Ag crystallites are observed at the interface (Fig. 3c). This is in contrast to the findings when the conventional OG frit is used: there Ag crystallites precipitate from the supersaturated OG frit upon cooling or regrow by an eutectic reaction $^{5,6}$. It was generally accepted that a uniform distribution of a large number of Ag crystallites in the interface region has been recognized as a prerequisite for high current flow efficiency in conventional $\mathrm{Si}$ solar cells ${ }^{26}$.
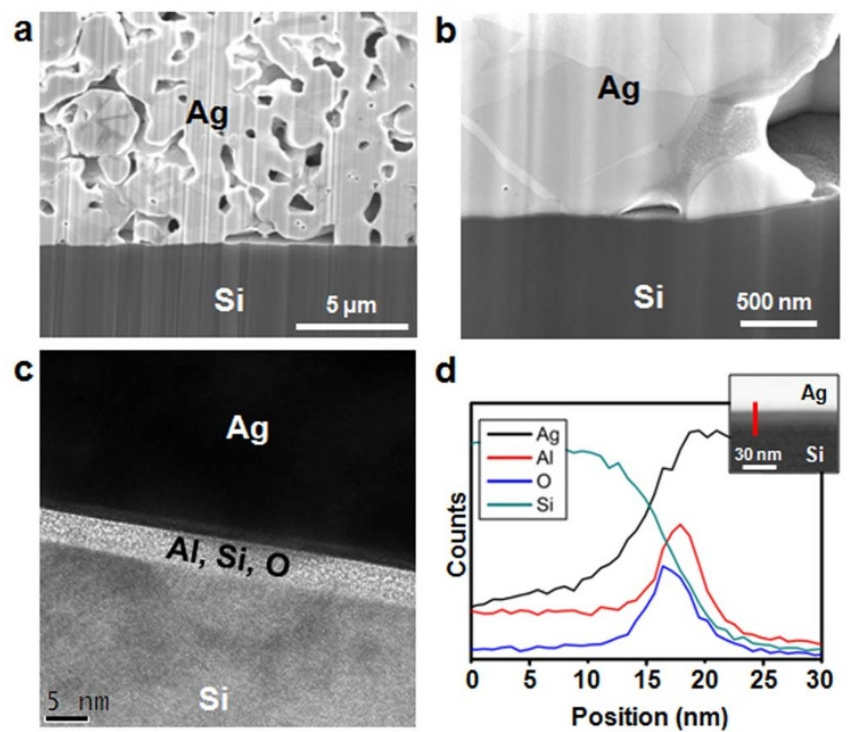

Figure $3 \mid$ Cross section of Ag electrode. SEM images obtained from the cross section of the contact between the Ag electrode and the Si wafer showing: (a) Sintered Ag electrode on the Si wafer; (b) Flat surface of the Ag particle in contact with the Si wafer surface. (c) Bright field TEM image obtained from the cross section of the contact between the Ag electrode and the Si wafer; (d) EDS line profile along the red line marked in the inset (dark field TEM image) showing enrichment of $\mathrm{Al}$ and $\mathrm{O}$ in the interface layer. The ultra-thin interface layer $(\sim 5 \mathrm{~nm})$ between the Ag electrode and the $\mathrm{Si}$ wafer enables efficient carrier transfer through the interface by direct tunneling, thus finally results in the high cell efficiency of the solar cell. 

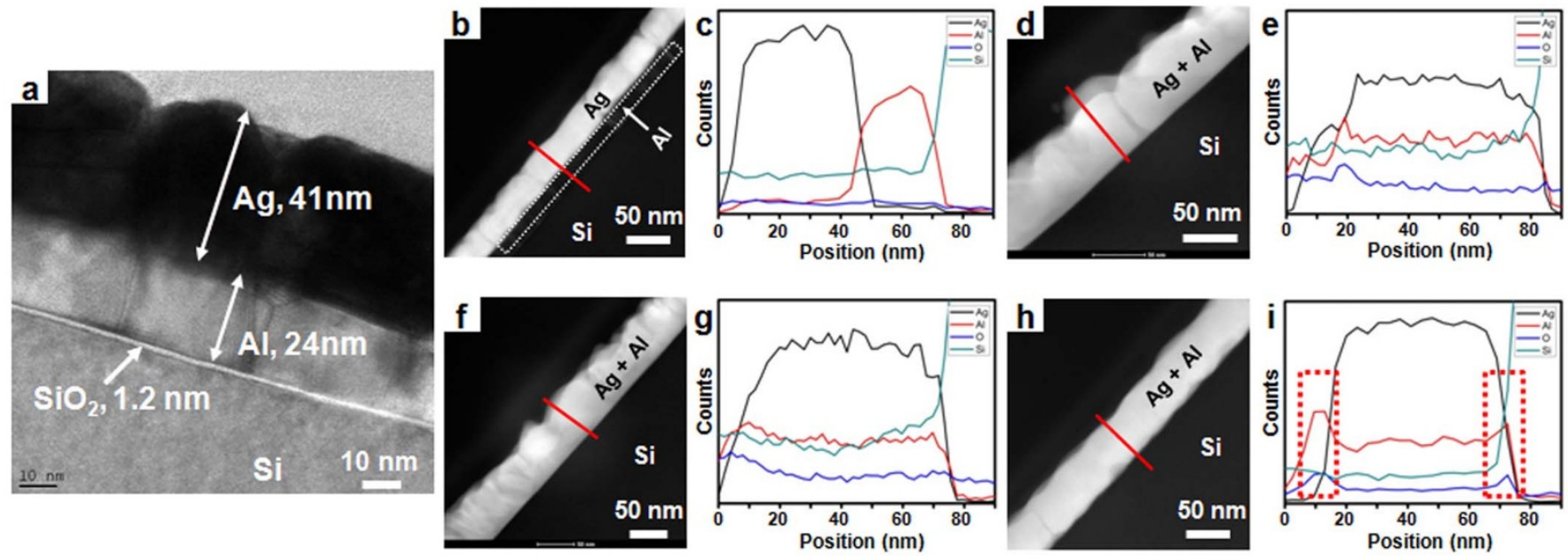

Figure $4 \mid$ Mechanism studies in Ag-Al-Si layers. Evaporation of Al and Ag thin layers on the Si substrate. (a) Bright field TEM image showing Ag and Al layers deposited on the Si wafer; (b), (d), (f), (h) Dark field TEM images showing the deposited layer on the Si wafer before heat treatment and after heating up to 573, 673 and $873 \mathrm{~K}$, respectively; (c), (e), (g), (i) EDS line profiles across the deposited layer before heat treatment and after heating up to 573, 673 and $873 \mathrm{~K}$, respectively. (d-e) Interdiffusion of $\mathrm{Al}$ and $\mathrm{Ag}$ at the interface forms an $\mathrm{Al}-\mathrm{Ag}$ solid solution layer at $573 \mathrm{~K}$. (h-i) The oxidation of $\mathrm{Al}$ occurs by the redox reaction of $4 / 3 \mathrm{Al}+\mathrm{SiO}_{2} \rightarrow 2 / 3 \mathrm{Al}_{2} \mathrm{O}_{3}+\mathrm{Si}$ at the interface between the $\mathrm{Al}$ - $\mathrm{Ag}$ solid solution layer and the $\mathrm{Si}$ wafer.

Contact formation mechanism. In order to investigate the contact formation mechanism, a separate experiment was performed by depositing thin $\mathrm{Al}$ and $\mathrm{Ag}$ layers sequentially on the $\mathrm{Si}$ wafer surface using an evaporator (Fig. 4a). The native $\mathrm{SiO}_{2}$ film with a thickness of $\sim 1.2 \mathrm{~nm}$ was present on the Si wafer surface. Before heat treatment, the $\mathrm{Al}$ and $\mathrm{Ag}$ layers were well separated (Figs. $4 \mathrm{~b}$, $4 \mathrm{c})$. The deposited samples were heated with a heating rate of $40 \mathrm{~K} / \mathrm{s}$ up to 573,673 , and $873 \mathrm{~K}$, and holded for $1 \mathrm{~min}$ before cooling to room temperature. After heating up to $573 \mathrm{~K}$, the composition profiles of $\mathrm{Al}$ and $\mathrm{Ag}$ across the deposited layer was almost constant (Figs. 4d, 4e), indicating that Al diffuses into the Ag layer due to relatively larger solubility of $\mathrm{Al}$ in $\mathrm{Ag}$ (13 at\% at $573 \mathrm{~K}$ ). After heating up to $673 \mathrm{~K}$ (Figs. $4 \mathrm{f}, 4 \mathrm{~g}$ ) and $773 \mathrm{~K}$ (not shown), same type of composition profile was obtained across the deposited layer. However, after heating up to $873 \mathrm{~K}$ (Figs. 4h, 4i), $\mathrm{Al}$ and $\mathrm{O}$ enriched regions were observed at both ends of the deposited layer (marked in Fig. 4i), indicating that selective oxidation of $\mathrm{Al}$ occurs as the temperature becomes higher. At the interface between the deposited layer and the $\mathrm{Si}$ wafer, the oxidation of $\mathrm{Al}$ occurs by the redox reaction of $4 / 3 \mathrm{Al}+\mathrm{SiO}_{2} \rightarrow 2 / 3 \mathrm{Al}_{2} \mathrm{O}_{3}+\mathrm{Si}, \Delta \mathrm{G}^{0}(\mathrm{~J} / \mathrm{mol})=$ $-207010+32.42 \mathrm{~T}$ due to the presence of the native $\mathrm{SiO}_{2}$ layer. Therefore, the native $\mathrm{SiO}_{2}$ layer reduces to $\mathrm{Si}$ when $\mathrm{Al}_{2} \mathrm{O}_{3}$ forms ${ }^{27}$.

Based on the results of the simulation and the deposition experiment, we propose that the contact formation during screen printing proceeds via three main steps: formation of SCL wetting layer between $\mathrm{Ag}$ particles and crystallization of $\mathrm{MG} \rightarrow$ formation of $\mathrm{Al}-\mathrm{Ag}$ eutectic liquid film $\rightarrow$ sintering of $\mathrm{Ag}$ particle and electrode contact formation, as schematically illustrated in Fig. 5. Before the firing process, the Ag and MG particles are randomly distributed in the screen printed paste (Fig. 5a). As the temperature is raised during the firing process, the MG in the paste transforms into the SCL state and fill the gap between Ag particles by the capillary force (Fig. 5b). Since the heating rate is very high during firing, crystallization of the SCL occurs shortly after wetting on the Ag particles. At the same time, interdiffusion of $\mathrm{Al}$ and $\mathrm{Ag}$ occurs at the interface between the MG wetting layer and the Ag particle (Fig. 5c). As the temperature increases further, binary Al-Ag eutectic reaction occurs at the interface (Al-Ag eutectic temperature, $840 \mathrm{~K}$, Fig. $5 \mathrm{~d}$ ). Since the viscosity of general metals in their liquid state is 1 to $10 \mathrm{mPa} \cdot \mathrm{s}$, it is expected that the Al-Ag eutectic liquid can wet the Ag particle surface, accelerating the sintering of Ag particles (Fig. 5e). Also, the Al-Ag eutectic liquid layer flattens the original spherical shape of the Ag particles at the contact region with the Si substrate (Fig. 5f). Additional eutectic reactions of binary $\mathrm{Al}-\mathrm{Si}(850 \mathrm{~K})$ and ternary $\mathrm{Ag}-\mathrm{Al}-\mathrm{Si}(840 \mathrm{~K})^{28}$ are possible at the contact region with the Si substrate. The presence of the eutectic liquid at the peak firing temperature leads to the formation of an ultra-thin interface layer between the Ag electrode and the Si wafer (Fig. 3c) during cooling. After cooling the resulting ultrathin layer is enriched in $\mathrm{Al}$ and $\mathrm{O}$ as shown in Fig. 3d (Fig. 5g).

During contact formation, there are two important steps: flow of the SCL into the channel between the Ag particle (as can be seen in the simulation result mentioned above); and flow of the eutectic liquid by which the sintering process and contact formation can be completed. Here, the fluidic behavior of the Al-Ag eutectic liquid was predicted using CFD simulation mentioned above. The result shows that the Al-Ag eutectic liquid forms a wetting layer on the Ag particles and the Si wafer surface within a remarkably short time of $0.0003 \mathrm{sec}$ (Fig. 6, Supplementary Information VI for the DFT simulation of the interfacial energies and Supplementary Information VII for the input parameters of the CFD simulation).

Evaluation of cell efficiency. Generally, conventional Ag paste containing the OG frit is sintered by firing up to $1073 \mathrm{~K}$, and the specific resistance of the resulting electrode is $3-5 \mu \Omega \mathrm{cm}^{29}$. However, in our study, the specific resistance of the electrode is $2.96 \mu \Omega \mathrm{cm}$ in spite of the lower firing temperature of $873 \mathrm{~K}$. Also, $\mathrm{Al}$ atoms in the MG frit induce binary and ternary eutectic reactions with $\mathrm{Ag}$ and $\mathrm{Si}$ atoms, leading to the formation of a $\sim 5 \mathrm{~nm}$ thick ultra-thin interface layer (Fig. 3c). Such a thin interface layer enables efficient carrier transfer through the interface by direct tunneling, thus significantly decreasing the contact resistance between Ag electrode and $\mathrm{Si}$ wafer. The contact resistance of the electrode is measured to be 0.18 and $0.37 \mathrm{~m} \Omega \mathrm{cm}^{2}$ for p-type emitter and ntype BSF (Back Surface Field), respectively, which is in the same range of $0.1-0.3 \mathrm{~m} \Omega \mathrm{cm}^{2}$ as for electro-plated electrodes. Such an improved contact resistance implies that the cell performance is comparable to that of the cell fabricated using an electroplating method. To evaluate the cell efficiency, interdigitated back contact (IBC) solar cells were fabricated using an elecrode paste containing Al-based MG frit. IBC cell design was adopted since it demonstrates the highest efficiency among the Si solar cells developed until now. The higher cell efficiency is mainly attributed to elimination of the 


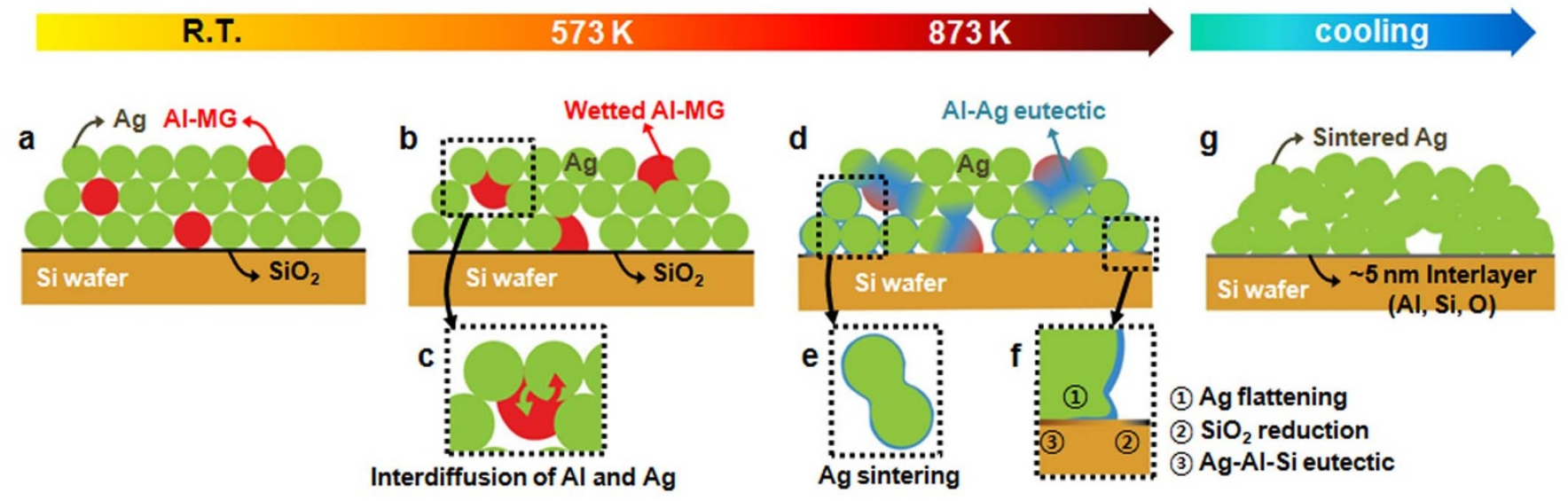

Figure $5 \mid$ Electrode contact formation mechanism. (a) Cross section of Al-MG/Ag paste printed on Si wafer. Green, red, yellow, and black represent silver, $\mathrm{Al}_{85} \mathrm{Ni}_{5} \mathrm{Y}_{8} \mathrm{Co}_{2} \mathrm{MG}$ (Metallic Glass), Si wafer, and native $\mathrm{SiO}_{2}$ layer, respectively. (b) Al-MG particle spontaneously flows into the channel between the Ag particles during firing process. Since the contact angle between the MG and the $\mathrm{Ag}$ particles is below $90^{\circ}$ and the viscosity of the MG is decreases in its SCL (supercooled liquid) region, the MG has a reasonably high driving force to fill the gap between Ag particles by the capillary effect. (c) Interdiffusion of $\mathrm{Ag}$ and $\mathrm{Al}$ occurs at the interface. (d) At the peak temperature $(873 \mathrm{~K})$ of the firing process, binary Al-Ag eutectic reaction occurs at the interface. Blue layer represents the Al-Ag eutectic liquid. (e) The Al-Ag eutectic liquid accelerates the sintering of Ag particles. (f) 1 . Al-Ag eutectic liquid layer flattens the originally spherical $\mathrm{Ag}$ particle at the contact region with the $\mathrm{Si}$ wafer; 2 . The native $\mathrm{SiO}_{2}$ layer on the $\mathrm{Si}$ wafer reduces to $\mathrm{Si}$ by $\mathrm{Al}$ in the $\mathrm{Al}-\mathrm{Ag}$ eutectic liquid: $4 / 3 \mathrm{Al}+\mathrm{SiO}_{2} \rightarrow 2 / 3 \mathrm{Al}_{2} \mathrm{O}_{3}+\mathrm{Si}$; . Additional eutectic reactions of binary Al-Si $(850 \mathrm{~K})$ and ternary Ag-Al-Si $(840 \mathrm{~K})$ occur at the contact region with the Si substrate. $(\mathrm{g})$ The presence of the eutectic liquid at the peak firing temperature leads to the formation of an ultra-thin interface layer between the Ag electrode and the Si wafer during cooling. Grey layer represents the ultra-thin interface layer.

front shading losses by placing all electrodes at the back of the cell. The fabricated cells exhibit an energy conversion efficiency of $20.30 \%$ (Table 1), which is the highest record reported for screen-printed IBC solar cells so far $^{30,31}$. Cell efficiency of $20.30 \%$ is acquired using commerciallized size $\left(154.8 \mathrm{~cm}^{2}\right)$ of Si solar cell. Furthermore, we fabricated the solar cell using the same Ag paste for both of p-type emitter and n-type BSF, which would be highly advantageous in commercializing the screen-printed solar cell using Al-based MG frit. Such a high cell efficiency is mainly attributed to the lower contact resistance which can be achieved by securing a very thin interface layer ( $\sim 5 \mathrm{~nm}$, Fig. 3c) beneath the Ag electrode. The thickness of the interface layer becomes much larger, generally over $100 \mathrm{~nm}$, when the conventional OG frit is used ${ }^{32}$. Comparison of the I-V parameters (Table 1) of the screen printed IBC solar cell fabricated using a MG frit (SPC) and those of the electrodeposition processed solar cell (EPC) shows that the cell performance of the SPC is comparable to that of the EPC. The mechanical stability of the solar cell fabricated using a MG frit is
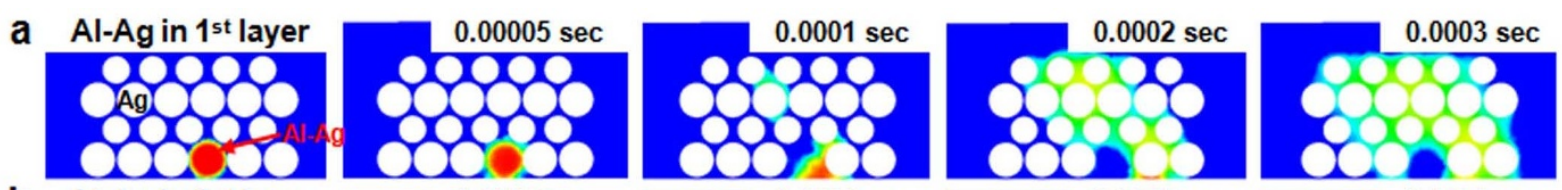

b $\mathrm{Al}-\mathrm{Ag}$ in $2^{\text {nd }}$ layer
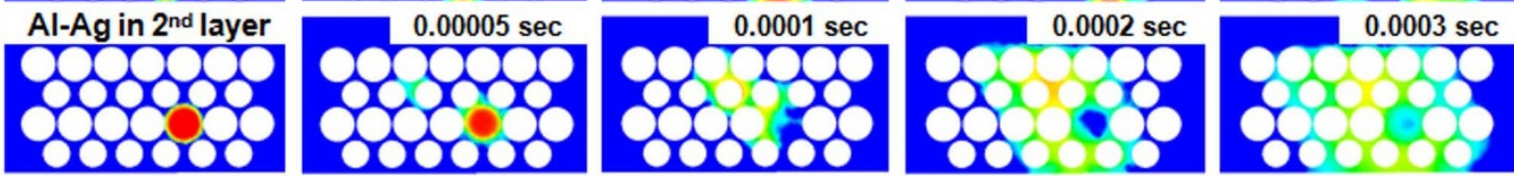

C Al-Ag in $3^{\text {rd }}$ layer
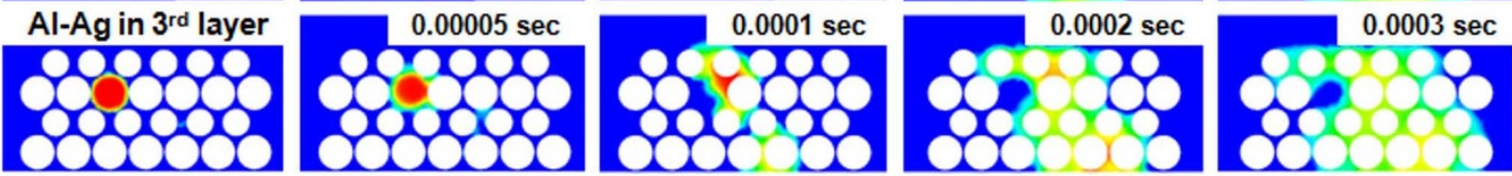

d Si wafer surface
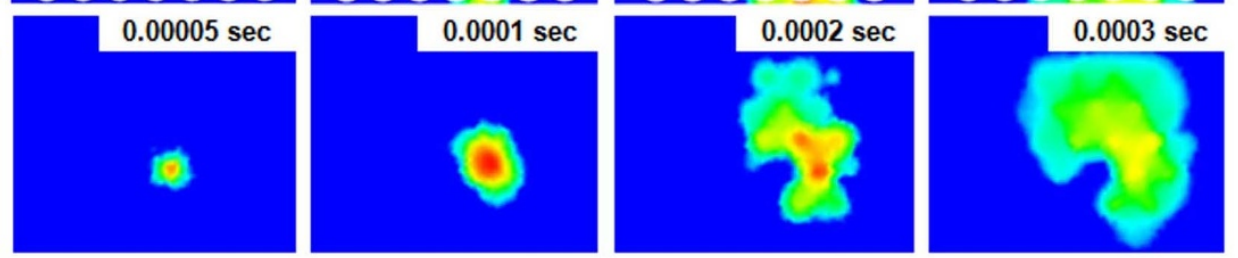

Figure 6 | Simulation of fluidic behavior of Al-Ag eutectic alloy. Al-Ag liquid alloy volume fraction contour plots at cross sections of the Ag electrode model (Same model described in Fig. 2a except that the MG balls are substituted by Al-Ag balls) where the Al-Ag alloys are located in the (a) first, (b) second, and (c) third layer from the bottom. White balls represent Ag particles. Volume fraction of Al-Ag alloy is displayed with the color ranging from blue (minimum value) to red (maximum value) on the contour plots. (d) Al-Ag alloy volume fraction contour plots of Si substrate. Since formation of the eutectic liquids are possible at the peak firing temperature $(873 \mathrm{~K})$, the eutectic liquid can form wetting layer on the Ag particles and on the $\mathrm{Si}$ substrate in a remarkably short time $(\sim 0.0003 \mathrm{sec})$. 
Table 1 | Comparison of I-V parameters of solar cells fabricated using screen printing method and electroplating method (cell area: $154.8 \mathrm{~cm}^{2}$ )

\begin{tabular}{|c|c|c|c|c|c|c|}
\hline & $J_{s c}^{[a]}$ & $V_{o c}^{[b]}$ & $R_{s}^{[c]}$ & $\mathrm{R}_{\mathrm{sh}}{ }^{[\mathrm{dd}]}$ & $\mathrm{FF}^{[\mathrm{e}]}$ & $\eta^{[f]}$ \\
\hline & 40.8 & 680 & 0.63 & $\geq 6,000$ & 79.35 & 22.02 \\
\hline $\begin{array}{l}\text { Screen printing } \\
\text { nethod }\end{array}$ & 40.8 & 672 & 1.11 & $\geq 10,000$ & 74.26 & 20.30 \\
\hline
\end{tabular}

$[\mathrm{a}]]_{\mathrm{sc}}\left(\mathrm{mA} / \mathrm{cm}^{2}\right)$ : short-circuit current density, $[\mathrm{b}] \mathrm{V}_{\mathrm{oc}}(\mathrm{mV})$ : open-circuitvoltage, $[c] \mathrm{R}_{\mathrm{s}}\left(\Omega \mathrm{cm}^{2}\right)$ : series resistance, [d] $R_{s h}\left(\Omega \mathrm{cm}^{2}\right)$ : shunt resistance, [e] FF (\%): fill factor, [f] $\eta(\%)$ : cell efficiency

not affected by the crystallized metallic glass which is known to be brittle, since eutectic reactions between crystallized product, $\mathrm{Ag}$ and $\mathrm{Si}$ occurs during the firing process. Therefore, the use of the MG frit in the electrode paste can significantly enhance the competitiveness of the screen printing process which will eventually become superior to that of electroplating or deposition processes.

\section{Discussion}

We have achieved a significant improvement in the quality of the contact between the Ag electrode and the Si emitter using a MG frit in the paste for screen printing. The dramatic improvement of the contact quality is attributed to: (i) the spontaneous flowability of the SCL to fill the cavity between the Ag particles; (ii) the efficiency in sintering to form a sound $\mathrm{Ag}$ electrode on the emitter surface; and (iii) the existence of eutectic reactions enabling to form an ultra-thin layer and a larger contact area between the $\mathrm{Ag}$ electrode and the $\mathrm{Si}$ emitter. The solar cell fabricated using such a good contact electrode exhibits an energy conversion efficiency of $20.30 \%$, which is the highest efficiency reported so far for screen printed solar cells.

\section{Methods}

The electrode paste was prepared by mixing Ag particles (diameter: $\sim 1 \mu \mathrm{m}$ ), $\mathrm{Al}_{85} \mathrm{Ni}_{5} \mathrm{Y}_{8} \mathrm{Co}_{2} \mathrm{MG}$ particles (diameter: $<5 \mu \mathrm{m}$, fabricated in Phoenix Scientific Industries Ltd.) and organic vehicles. Butyl carbitol and ethyl cellulose-based chemicals were used for the organic vehicles. The volume fraction of Al-based MG in the electrode paste was $\sim 6 \mathrm{vol} \%$ excluding the organic vehicles. The pre-mixed paste was 3 -roll-milled, and then re-mixed in the paste mixer to remove air bubbles. The electrode pattern was prepared by screen printing the paste on single crystalline $\mathrm{Si}$ wafers, followed by drying in an IR-belt furnace at $423 \mathrm{~K}$ for $5 \mathrm{~min}$ to evaporate the organics in the paste. The dried wafer was fired using a rapid thermal process in an IRbelt furnace from room temperature up to $873 \mathrm{~K}$ with a ramping speed of $75 \mathrm{~K} / \mathrm{s}$.

1. Hilali, M. M., To, B. \& Rohatgi, A. A review and understanding of screen-printed contacts and selective-emitter formation. in Proceedings of the $14^{\text {th }}$ Workshop on Crystalline Silicon Solar Cells and Modules, 109-116 (Colorado, USA, 2004).

2. Hilali, M. M. Understanding and development of manufacturable screen-printed contacts on high sheet-resistance emitters for low-cost silicon solar cells (Ph.D. thesis, Georgia institute of Technology, 2005).

3. Li, T. et al. Improvement on electrical properties of screen-printed crystalline silicon solar cells by light-induced electroplating of silver. Applied Mechanics and Materials 71, 778-781 (2011)

4. Bartsch, J., Mondon, A., Schetter, C., Hörteis, M. \& Glunz, S. W. Copper as conducting layer in advanced front side metallization processes for crystalline silicon solar cells, exceeding $20 \%$ on printed seed layers. in Proceedings of the 35 th IEEE Photovoltaic Specialists Conference, 1299-1303 (Honolulu, HI, USA, 2010).

5. Hilali, M. M. et al. Effect of glass frit chemistry on the physical and electrical properties of thick-film Ag contacts for silicon solar cells. J. Electronic Mater 35, 2041-2047 (2006).

6. Schubert, G., Huster, F. \& Fath, P. Current transport mechanism in printed Ag thick film contacts to an n-type emitter of a crystalline silicon solar cell. in Proceedings of the $19^{\text {th }}$ European Photovoltaic Solar Energy Conference, 813-816 (Paris, 2004).

7. Kim, S. Y. et al. Replacement of oxide glass with metallic glass for Ag screen printing metallization on Si emitter. Appl. Phys. Lett. 98, 222112 (2011).

8. Kim, S. J. et al. Exploiting metallic glasses for $19.6 \%$ efficient back contact solar cell. Appl. Phys. Lett. 101, 064106 (2012).

9. Jee, S. S. et al. Enhancement of electrical conductivity of thick silver electrode using a tailored amorphous alloy. Appl. Phys. Lett. 101, 084104 (2012).
10. Kuo, Y. K. et al. Measurement of low-temperature transport properties of Cu-based Cu-Zr-Ti bulk metallic glass. Phys. Rev. B 74, 014208-014214 (2006).

11. Mazurin, O. V., Streltsina, M. V. \& Shvaiko-Shvaikovskaya, T. P. Handbook of glass data. Part C: Ternary silicate glasses (Elsevier, Amsterdam, 1987).

12. Kumar, G., Desai, A. \& Schroers, J. Bulk metallic glass: The smaller the better. Adv Mater. 23, 461-476 (2011).

13. Johnson, W. L. et al. Beating crystallization in glass-forming metals by millisecond heating and processing. Science 332, 828-833 (2011).

14. Furukawa, A. \& Tanaka, H. Inhomogeneous flow and fracture of glassy materials. Nature Materials 8, 601-609 (2009).

15. Liu, Y. H. et al. Super Plastic Bulk Metallic Glasses at Room Temperature. Science 315, 1385-1388 (2007).

16. Kumar, G., Tang, H. X. \& Schroers, J. Nanomoulding with amorphous metals. Nature 457, 868-872 (2009).

17. Ballif, C., Huljić, D. M., Willeke, G. \& Hessler-Wyser, A. Silver thick-film contacts on highly doped n-type silicon emitters: Structural and electronic properties of the interface. Appl. Phys. Lett. 82, 1878-1880 (2003).

18. Saotome, Y., Roppongi, K., Zhang, T. \& Inoue, A. Characteristic behavior of $\mathrm{La}_{55} \mathrm{Al}_{25} \mathrm{Ni}_{20}$ amorphous alloy under rapid heating. Mater. Sci. Eng. A 304, 743-746 (2001).

19. Thomas, H., Thomas, V., Ramanujan, R. V. \& Anantharaman, M. R. Thermal and structural analysis of the crystallization dynamics of metallic glass $\mathrm{Fe}_{40} \mathrm{Ni}_{38} \mathrm{~B}_{18} \mathrm{Mo}_{4}$. J. Optoelectron. Adv. Mater. 11, 1094-1099 (2009).

20. Brandes, E. A. \& Brook, G. B. Smithells metals reference book 7th edition, (Butterworth-Heinemann Ltd, Oxford, 1992).

21. Howe, J. M. Interfaces in materials: Atomic structure, thermodynamics and kinetics of solid-vapor, solid-liquid and solid-solid interfaces (John Wiley \& Sons, Inc., New York, 1997).

22. Xu, D., Lohwongwatana, B., Duan, G., Johnson, W. L. \& Garland, C. Bulk metallic glass formation in binary $\mathrm{Cu}$-rich alloy series $-\mathrm{Cu}_{100-\mathrm{x}} \mathrm{Zr}_{\mathrm{x}}(\mathrm{x}=34,36,38.2$, 40 at.\%) and mechanical properties of bulk $\mathrm{Cu}_{64} \mathrm{Zr}_{36}$ glass. Acta Materialia 52, 2621-2624 (2004).

23. Li, Y. et al. Enhancement of glass-forming ability and corrosion resistance of $\mathrm{Zr}$ based Zr-Ni-Al bulk metallic glasses with minor addition of Nb. J. Appl. Phys. 110, 023513-023517 (2011).

24. Nakamura, K., Isaka, T., Funakoshi, Y., Tonomura, Y., Machida, T. \& Okamoto, K. Development of $20 \%$ efficiency mass production Si solar cells. in Proceedings of the 20th European Photovoltaic Solar Energy Conference, 789-792 (Barcelona, Spain, 2005).

25. Zhang, Y., Yang, Y., Zheng, J., Hua, W. \& Chen, G. Thermal properties of glass frit and effects on Si solar cells. Materials Chemistry and Physics 114, 319-322 (2009).

26. Hörteis, M., Gutberlet, T., Reller, A. \& Glunz, S. W. High-temperature contact formation on $\mathrm{n}$-type silicon: Basic reactions and contact model for seed-layer contacts. Adv. Funct. Mater. 20, 476-484 (2010).

27. Zhang, X., Roelofs, H., Lemgen, S., Urlau, U. \& Subramanian, S. V. Application of thermodynamic model for inclusion control in steelmaking to improve the machinability of low carbon free cutting steels. Steel Research int. 75, 314-321 (2004).

28. Humpston, G. Liquidus and solidus temperatures in the Ag-Al-Ge-Si system. J. Mater. Sci. Lett. 10, 1069-1071 (1991).

29. Schubert, G. Thick Film Metallisation of Crystalline Silicon Solar Cells. (Ph.D. thesis, University of Konstanz, 2006).

30. Lamers, M. W. P. E. et al. Towards $21 \%$ efficient N-CZ IBC based on screen printing. in Proceedings of the $26^{\text {th }}$ European Photovoltaic Solar Energy Conference and Exhibitions, 2239-2242 (Hamburg, Germany, 2011).

31. Castaño, F. J. et al. Industrially feasible $>19 \%$ efficiency IBC cells for pilot line processing. in Proceedings of the 37th IEEE Photovoltaic Specialists Conference, 1038-1042 (Seattle, WA, USA, 2011).

32. Hilali, M. M. et al. Effect of Ag particle size in thick-film Ag paste on the electrical and physical properties of screen printed contacts and silicon solar cells. J. Electrochem. Soc. 153, A5-A11 (2006).

\section{Acknowledgements}

We would like to thank Hyoeng Ki Kim and Min Chul Song for solar cell fabrication (Samsung SDI CO. LTD). K. R. Lim, W. T. Kim, D. H. Kim and J. Eckert acknowledge the support by the Global Research Laboratory Program of the Korean Ministry of Education, Science and Technology.

\section{Author contributions}

S.Y.K., J.M.P., K.H.P., K.R.L., E.S.L. fabricated the metallic glasses and analyzed their properties; S.J.K., S.S.J. fabricated the $\mathrm{Ag} / \mathrm{MG}$ paste and measured its electrical properties; S.J.K., S.S.J., S.C.P. fabricated the solar cell and measured the cell efficiency; J.H.L., I.Y.S., J.C.P. carried out the microscopy experiments; S.Y.K., S.M.L., I.T.H., D.H.K., E.S.L. designed the experiments and analyzed the experimental results; S.Y.K., E.A.C. calculated the deformation behavior of metallic glasses and interfacial energies. S.Y.K., S.J.K., W.T.K., J.E., D.H.K., E.S.L. wrote the paper. 


\section{Additional information}

Supplementary information accompanies this paper at http://www.nature.com/ scientificreports

Competing financial interests: The authors declare no competing financial interests. BY NC ND NonCommercial-NoDerivs 3.0 Unported license. To view a copy of this license, visit http://creativecommons.org/licenses/by-nc-nd/3.0

How to cite this article: Kim, S.Y. et al. Capillary flow of amorphous metal for high performance electrode. Sci. Rep. 3, 2185; DOI:10.1038/srep02185 (2013). 